\title{
Posterior Tibial Vein
}

National Cancer Institute

\section{Source}

National Cancer Institute. Posterior Tibial Vein. NCI Thesaurus. Code C33386.

A vein in the foot that is formed by the union of the external and internal plantar veins and which becomes the popliteal vein. 